\title{
Internacionalização, desindustrialização precoce e subdesenvolvimento recente sob a ótica de Furtado
}

\author{
Rossandra Oliveira Maciel de Bitencourt* \\ Pollyanna Rodrigues Gondin **
}

\begin{abstract}
Resumo
À luz da interpretação de Celso Furtado, com ênfase nos conceitos de desenvolvimento e homogeneidade social, buscamos compreender se o subdesenvolvimento recente no Brasil está associado ao processo de desindustrialização. Para tanto, o presente trabalho analisa as variáveis: importação, exportação, Investimento Direto Externo (IDE) e Formação Bruta de Capital Fixo (FBCF) nos anos 2000. Os dados foram coletados na Federação das Indústrias do Estado do Paraná, Banco Central do Brasil e Instituto de Pesquisa Econômica Aplicada. A pesquisa é explicativa com abordagem de análise quantitativa. Os resultados apontam que o Brasil está distante da autonomia tecnológica à qual Furtado fez referência. No âmbito da internacionalização, a dependência externa se acentua, visto que importamos produtos de média-alta e alta tecnologia. Outra evidencia é a relação inversa entre o aumento do IDE e a contração da FBCF. Sendo o desenvolvimento do progresso técnico uma das vias para a superação do subdesenvolvimento, constatamos que há muito a ser percorrido rumo ao desenvolvimento e à homogeneidade social.
\end{abstract}

Palavras-chave: Subdesenvolvimento; Internacionalização; Desindustrialização.

\section{Internationalization, premature deinsustrialization and recent underdevelopment under the perspective of Celso Furtado}

\begin{abstract}
According to Celso Furtado's interpretation, with an emphasis on the development's concept and social homogeneity, we seek to understand whether the recent underdevelopment in Brazil is associated in the deindustrialization process. Therefore, the present work analyse the variables: import, export, Foreign Direct Investment (FDI) and Gross Fixed Capital Formation (GFCF) in the 2000s. The data were collected in the Federation of Industries of the State of Paraná, Central Bank of Brazil and Institute of Applied Economic Research. It is an explanatory research with a quantitative analysis approach. The results show that Brazil is far from the technological autonomy which Furtado referred. In the scope of internationalization, external dependence is accentuated, since we import medium-high and high technology products. Another evidence is the inverse relationship between the increase in FDI and the contraction of GFCF. Since the development of technical progress is one of the ways to overcome underdevelopment, we find that a long way to go towards development and social homogeneity.
\end{abstract}

Keywords: Underdevelopment; Internationalization; Deindustrialization Process.

Classificação JEL: O1, O10, O11

\footnotetext{
* Doutora em Políticas Públicas pela Universidade Federal do Paraná (UFPR). E-mail: rossandra.maciel@yahoo.com.br

** Doutora em Políticas Públicas pela Universidade Federal do Paraná (UFPR) e Professora no Centro Internacional Universitário (UNINTER). E-mail: pollygondin@gmail.com.
} 


\section{Introdução}

Em seus ensaios e debates, Celso Furtado demonstra que na América Latina houve modernização, mas sem desenvolvimento, com valores diferentes dos países que alçaram voos rumo ao progresso técnico antecipadamente (tais como China, Japão, Coreia, entre outros). A modernização conservadora refere-se à mudança que moderniza, mas não transforma a estrutura, pois permanece com defasagem de métodos produtivos eficazes (FURTADO, 1992).

À luz da interpretação de Furtado, com ênfase nos conceitos de desenvolvimento e homogeneidade social, buscamos compreender se o subdesenvolvimento recente no Brasil está associado à intensificação do processo de desindustrialização precoce nos anos 2000. Como não é possível falar em desindustrialização sem considerar o comércio exterior, o presente trabalho apresenta uma síntese das seguintes variáveis: importação, exportação, Investimento Direto Externo (IDE) e Formação Bruta de Capital Fixo (FBCF).

Em relação ao processo de desindustrialização precoce, é relevante mencionar que nos países de renda per capita alta a desindustrialização faz parte da própria dinâmica de desenvolvimento da indústria. São economias que alcançaram alto nível de renda em função do processo de industrialização e que recentemente perderam relevância relativa em função do rápido crescimento dos segmentos de serviços. Essa desindustrialização relativa não implica, necessariamente, queda da renda per capita. Trata-se de um processo relativamente "natural" na medida em que as atividades de maior complexidade tecnológica relacionadas a serviços passam a ter maior participação relativa da renda (SILVA, 2014). Entretanto, esse não é o caso brasileiro. Conforme Lima (2017), no começo dos anos de 1970 a indústria brasileira era responsável por $27,4 \%$ do total de empregos. Já em 2015, esse valor caiu para 14,2\% segundo PNAD contínua.

No tocante à metodologia, com o objetivo de estudar a evolução do comércio exterior brasileiro por nível de Intensidade Tecnológica (IT), foram coletados dados junto à Federação das Indústrias do Estado do Paraná (FIEP) por meio de pesquisa de campo. Os dados fornecidos pela FIEP foram extraídos da base do Ministério da Economia, Indústria, Comércio Exterior e Serviços (MDIC). No que se refere ao IDE e à FBCF, os dados foram coletados junto ao Banco Central do Brasil e ao Instituto de Pesquisa Econômica Aplicada. Trata-se, portanto, de uma pesquisa explicativa com abordagem de análise quantitativa.

O presente artigo encontra-se dividido em cinco partes. Após esta introdução, analisamos os conceitos de desenvolvimento e homogeneidade social a partir de Celso Furtado. 
Na sequência, adentra-se à discussão sobre internacionalização, IDE e desindustrialização. Posteriormente, são apresentados os resultados desta pesquisa, e, por fim, são feitas as considerações finais acerca do que foi observado.

\section{Desenvolvimento e homogeneidade social}

Logo após a Segunda Guerra Mundial, o desenvolvimento socioeconômico passou a ser discutido em uma perspectiva de intervenção do Estado na economia, em detrimento de uma visão mais normativa, pouco histórica, que se restringia à diferença entre países desenvolvidos e subdesenvolvidos.

Esse é o cenário em que emerge a Comissão Econômica para América Latina e Caribe (CEPAL), fomentando um debate sobre a superação do subdesenvolvimento na América Latina. Para Raúl Prebisch, economista que se dedicou aos estudos cepalinos, a distinção entre países desenvolvidos e subdesenvolvidos estava essencialmente na histórica heterogeneidade do progresso técnico.

Como acoplar em uma sociedade o progresso técnico quando há um enorme contingente de mão de obra disponível? Essa problemática perpassa as raízes do processo de industrialização na América Latina e foi objeto de estudo de Celso Furtado junto à CEPAL. A principal crítica dessa vertente é que, na periferia, ou seja, nos países latino-americanos, o aumento da produtividade não produziu homogeneidade, como ocorreu nos países do centro, sendo essa uma das razões explicativas para o subdesenvolvimento.

Para Furtado (1992) a homogeneidade social implica a garantia do que é humanamente essencial a todos. Esse cenário se concretiza quando membros de uma sociedade satisfazem de forma apropriada as necessidades de alimentação, vestuário, moradia, acesso à educação, ao lazer e ao mínimo de bens culturais. Essa é a mudança estrutural necessária que a modernização conservadora não alcançou ao longo do século XX. Mas, ao contrário, agravou ainda mais a distribuição de renda e concentrou o capital, ou seja, manteve a heterogeneidade.

Na visão de Furtado, a modernização dos países latino-americanos é conservadora porque ampliou o processo de acumulação excedente - por meio do Processo de Substituição de Importações, porém a renda nesses países permaneceu concentrada. Ou seja, boa parte do contingente social não teve alcance e pouco se apropriou, ao passo que o desenvolvimento deveria preocupar-se com a distribuição do excedente gerado não só pelo salário, mas pela 
melhoria das condições de vida. Essa interpretação remete à associação entre subdesenvolvimento, desigualdade e heterogeneidade social.

Aprofundando essa reflexão, Furtado (1992) argumenta que a modernização conservadora no Brasil e na América Latina promoveu uma convulsão social, na medida em que ampliou a lacuna entre a penetração da moderna tecnologia no estilo de vida e nos processos produtivos. Permanecemos subdesenvolvidos porque o crescimento da produtividade está longe de ser condição suficiente para que se produza o verdadeiro desenvolvimento.

Desenvolvimento requer que produção e consumo andem juntos. A desarticulação entre ambos intensifica o subdesenvolvimento. A crítica furtadiana afirma, portanto, que estamos mais voltados às políticas anticíclicas de recuperação de crises do que propriamente a um projeto amplo de desenvolvimento. O subdesenvolvimento não é uma etapa do desenvolvimento, mas uma condição estrutural, o que torna necessário uma grande ruptura:

\begin{abstract}
O subdesenvolvimento é um desequilíbrio na assimilação dos avanços tecnológicos produzidos pelo capitalismo industrial a favor das inovações que incidem diretamente sobre o estilo de vida. Essa proclividade à absorção de inovações nos padrões de consumo tem como contrapartida atraso na adoção de métodos produtivos mais eficazes. É que os dois processos de penetração de novas técnicas se apoiam no mesmo vetor que é a acumulação. Nas economias desenvolvidas existe um paralelismo entre a acumulação nas forças (FURTADO, 1992, p. 9).
\end{abstract}

Nessa perspectiva, Furtado afirma que o crescimento da produtividade está longe de ser condição suficiente para que se produza o verdadeiro desenvolvimento, pois não conduz à redução da heterogeneidade social, ou pelo menos não o faz espontaneamente dentro dos mecanismos de mercado. Por outro lado, a homogeneização social é condição necessária, mas não suficiente para alcançar a superação do subdesenvolvimento. Esta precisa vir associada à criação de um sistema produtivo eficaz dotado de relativa autonomia tecnológica, o que requer: (a) descentralização de decisões que somente os mercados asseguram; (b) ação orientadora do Estado; (c) exposição à concorrência internacional.

[...] para penetrar nos mercados internacionais o caminho mais eficaz consiste em utilizar um misto de tecnologias: tirar partido da abundância de certos fatores primários e ao mesmo tempo apoiar-se em tecnologias de vanguarda. Essa situação particular requer certo grau de autonomia tecnológica, que não se obtém sem um esforço contínuo e crescente de aplicação de recursos na pesquisa científicotecnológica, particularmente de parte das empresas (FURTADO, 1992, p. 20).

Ainda que de forma breve, resgatamos a associação entre os conceitos de desenvolvimento e homogeneidade social por se traduzirem em categorias teóricas centrais na análise empírica que trazemos. Reconhecemos que, por se tratar de temas complexos, não 
devemos correr o risco de abordá-los de forma rasa. Sobretudo, porque ambos abrem um leque de elementos a serem aprofundados. Falar de homogeneidade implica adentrar nas fissuras de um processo de desenvolvimento impregnado de desigualdades sociais. E reconhecer a heterogeneidade é um dos passos para compreender as condicionalidades do subdesenvolvimento.

Logo, essas categorias norteiam a presente análise na medida em que Furtado afirma que a superação das condições estruturais do subdesenvolvimento impõe a necessidade da homogeneização social associada à criação de um sistema produtivo dotado de autonomia tecnológica e competitividade internacional. É partindo dessa constatação que damos sequência à presente análise, adentrando a seguir na relação entre internacionalização, investimento direto externo e desindustrialização.

\section{Internacionalização, investimento direto externo e desindustrialização}

Atualmente, a temática relacionada ao processo de desindustrialização brasileira é considerada central e tema de grande debate entre estudiosos. Desde a crise da dívida brasileira, nos anos de 1980, alguns autores voltaram seus estudos para esse fenômeno. Essa discussão se intensificou com a abertura comercial que ocorreu na década de 1990, marcada pelo abandono das políticas desenvolvimentistas e pela valorização cambial como ferramenta de controle da inflação. Deve-se considerar, também, que outros fatores e acontecimentos influenciaram o processo de desaceleração da indústria, como, por exemplo, as reformas liberais do Fundo Monetário Internacional (FMI) e do Banco Mundial e a pauta exportadora focada em commodities.

Contudo, de acordo com a corrente ortodoxa, o país passa, na verdade, por um processo de modernização da indústria, sendo que muitos dos autores desta corrente chegam a não reconhecer o processo de desindustrialização. Esses estudiosos argumentam que os indicadores utilizados para demonstrar esse processo se referem a um momento conjuntural relacionado a acontecimentos que poderiam dar a falsa ideia de desindustrialização. Conjuntamente, o período compreendido entre 1994 e 2002 foi marcado por fortes instabilidades, que contribuíram, de modo significativo, para que a produção industrial se desacelerasse mais rapidamente do que o PIB (FGV, 2010). Apesar disso, não existe, segundo essa corrente, evidências concretas de que esse processo esteja acontecendo.

Há também os que afirmam que o processo de desindustrialização está ocorrendo, tanto do ponto de vista dos dados quanto do ponto de vista do que estaria acontecendo no comércio 
e no dia a dia da economia brasileira em geral. De acordo com Oreiro e Feijó (2010), Marquetti (2002) foi um dos primeiros autores a apresentar um estudo que aponta para a desindustrialização brasileira como consequência do baixo investimento na economia. Além deste, vários autores se propuseram a estudar a temática, destacando-se: Bresser-Pereira (2008), Cano (2012), Bresser-Pereira e Marconi (2008), Oreiro e Feijó (2010).

Outra abordagem que se sobressai é a investigação feita por Sarti e Laplane (2002). Os autores analisaram o processo de internacionalização produtiva no Brasil nos anos 1990 e apontaram diferenças importantes com relação às experiências em outros países: México, Coreia do Sul e China, destacando que o Brasil sofreu uma internacionalização "introvertida". Esse processo se caracterizou pela transferência da propriedade de empresas nacionais para investidores estrangeiros, sem contrapartida proporcional de investimentos de empresas brasileiras no exterior, e pela assimetria entre o expressivo incremento de volume e conteúdo importados no mercado e na produção doméstica. Nessa contradição, a estrutura produtiva muito mais eficiente contribuiu para agravar a vulnerabilidade externa da economia brasileira nos anos 1990 (SARTI; LAPLANE, 2002).

Um elemento que conecta o debate sobre internacionalização e desindustrialização diz respeito ao Investimento Direto Externo (IDE). Na década de 1990, os autores supracitados constataram que embora o investimento estrangeiro promovesse aumento expressivo da eficiência e da competitividade em setores relativamente defasados a padrões internacionais, $o$ principal instrumento utilizado era a importação massiva de tecnologia, sem contrapartida equivalente no aumento das exportações. Nesses termos, o baixo poder de indução do IDE nos anos 1990 não favoreceu a industrialização:

\begin{abstract}
A tradicional fragilidade das cadeias produtivas locais, agravada pela estratégia de estabilização adotada - câmbio valorizado e juros elevados -, fazia com que parte importante do impulso dinâmico dos investimentos fosse direcionada para o exterior, alimentando a importação de equipamentos, de componentes e de tecnologia (SARTI; LAPLANE, 2002, p. 64).
\end{abstract}

Nos anos 1990, a mudança mais marcante no plano produtivo foi, sem dúvida, o aumento significativo do grau de internacionalização. Para Sarti e Laplane (2002), a dimensão mais visível da abertura econômica foi a patrimonial, ou seja, a internacionalização do sistema empresarial. Todavia, no caso brasileiro, esse processo assumiu a forma de uma desnacionalização, visto que a transferência da propriedade de empresas nacionais para estrangeiros ultrapassou de longe a aquisição de ativos produtivos no exterior por brasileiros.

A Formação Bruta de Capital Fixo (FBCF) também foi objeto de análise dos autores 
supracitados, os quais constataram que esta não acompanhou o crescimento do IDE. Essa contradição evidencia a pequena contribuição do IDE para o aumento da taxa de investimento na economia:

A análise da composição do IDE mostra que, no caso brasileiro (assim como em outros países da América Latina e diferentemente da China), uma parte considerável foi destinada à aquisição de ativos já existentes. Essa é a razão pela qual os investimentos estrangeiros que ingressaram no país pouco contribuíram para aumentar a FBCF na economia (SARTI; LAPLANE, 2002, p. 68).

Diferentemente do IDE destinado à construção de novos ativos, aquele orientado à compra de ativos já existentes, públicos ou privados, não pode ser caracterizado como investimento no sentido macroeconômico. Nesses casos, a relação do IDE com o crescimento do produto é, na melhor das hipóteses, indireta.

Em suma, sabe-se que no início do século XX o Brasil reduziu fronteiras no âmbito da internacionalização. Contudo, apesar de os indícios aqui explanados apontarem para um possível cenário de desindustrialização, não há unanimidade quanto ao assunto. Essa lacuna abre espaço para uma investigação com ênfase na dinâmica recente de segmentos diferentes da indústria, principalmente sob a ótica dos seus padrões tecnológicos, conforme veremos a seguir.

\section{Desindustrialização, investimento direto externo e formação bruta de capital fixo no Brasil}

De acordo com Cardoso de Mello (1982), o Brasil passou por um período de industrialização restringida entre 1933 e 1955 e, após esse período, iniciou-se um período de industrialização pesada. Entretanto, o caráter tardio e periférico da industrialização continuou apresentando as seguintes especificidades (SILVA; LAPLANE, 1994, p. 86):

[...] menor dinamismo da produção de bens de capital, presença marcante das empresas de capital estrangeiro de origem diversificada, forte setor produtivo estatal principalmente na área de insumos básicos, estrutura patrimonial das empresas nacionais privados fragilizadas, baixo esforço tecnológico tanto das empresas nacionais como das estrangeiras (estratégias de produto e de processo imitativas e defasadas), baixos coeficientes de importação (associados a níveis elevados de proteção tarifária e não-tarifária) e estratégias de crescimento voltadas principalmente para o mercado interno e apoiadas na continuidade do processo de substituição de importações.

Como resultado dos caminhos tomados durante o processo de industrialização brasileira, desde a década de 1980, ascendeu no debate acadêmico a tese da desindustrialização precoce. Dada a fragilidade da competitividade da indústria, a defesa dessa tese se baseia no fato de que 
ela estaria ocorrendo em função da abertura comercial, das reformas neoliberais e do estímulo às exportações de commodities por conta da sua elevada competitividade "vocacional" e, em alguma medida, pelo câmbio valorizado.

Apesar do debate sobre o processo de desindustrialização ter se acendido na década de 1980, foi após o período de 2008/2009 que este ganhou força. Isso se deve, principalmente, à queda significativa da indústria de transformação no PIB brasileiro, à redução da participação do emprego industrial no emprego total, à maior participação das commodities nas exportações e ao aumento das importações de bens manufaturados (SILVA, 2014).

De acordo com Cano (2012), a indústria deteriorou-se devido à ausência de políticas industriais e de desenvolvimento. Acrescentam-se, ainda, os juros elevados, a falta de investimento, o câmbio valorizado e a abertura comercial. Nesse âmbito, o autor elenca quatro fatores responsáveis por desencadear a desindustrialização precoce no Brasil:

a. Política cambial instaurada a partir do Plano Real, com câmbio excessivamente valorizado, diminuindo a competitividade internacional da indústria nacional;

b. Abertura comercial desregrada a partir de 1989, que juntamente com o câmbio valorizado reduziu o grau de proteção perante a concorrência internacional;

c. Taxa de juros elevada, inibindo o investimento e deixando a indústria vulnerável;

d. O investimento direto estrangeiro (CANO, 2012, p. 4-5).

Esse foi um cenário em que a produtividade e a competitividade da indústria brasileira caíram ao mesmo tempo em que o IDE americano e asiático migraram para a China em busca de trabalho barato, câmbio desvalorizado e alta competitividade.

Tabela 1 - Indicadores de participação no Produto Interno Bruto - Indústria (\% PIB) - 20002018

\begin{tabular}{c|c|c|c|c}
\hline Ano & Construção civil & $\begin{array}{c}\text { Eletricidade, gás, } \\
\text { água, esgoto e } \\
\text { limpeza urbana }\end{array}$ & Extrativa & Transformação \\
\hline 2000 & 6,96 & 3,14 & 1,38 & 15,27 \\
\hline 2005 & 4,59 & 3,37 & 3,15 & 17,36 \\
\hline 2010 & 6,27 & 2,81 & 3,33 & 14,97 \\
\hline 2015 & 5,74 & 2,39 & 2,15 & 12,24 \\
\hline 2017 & 4,77 & 2,63 & 1,67 & 12,25 \\
\hline 2018 & 4,46 & 2,84 & 2,99 & 11,31 \\
\hline
\end{tabular}

Fonte: Ipea-data.

Assim, houve perda de competitividade das exportações brasileiras, ao mesmo tempo em que aumentaram as importações de produtos chineses (CANO, 2012). A Tabela 1 evidencia

\footnotetext{
${ }^{1}$ Produção e distribuição.
} 
o presente argumento, indicando a queda expressiva da participação da Indústria de Transformação no PIB nos anos 2000.

Outro indicador que pode sinalizar a desindustrialização é o comércio exterior (MORCEIRO, 2012). Expressa a relação da economia brasileira com o restante do mundo em termos de balança comercial, e o IDE no tocante à evolução da competitividade da indústria e sua capacidade de inserção no mercado mundial.

No que se refere à evolução da balança comercial brasileira no período de 1997 a 2018, dados coletados em pesquisa de campo junto à Federação das Indústrias do Estado do Paraná (2019) demonstram, a princípio, uma situação favorável, visto que o saldo das exportações superou o das importações. Nessa mesma linha, a Taxa de Crescimento Anual Composta (Compound Annual Growth Rate - CAGR) ${ }^{2}$ reforça que, para o período analisado, a variação das exportações é superior à das importações, 7,45\% e 5,44\% respectivamente.

Ao desagregar as exportações e importações, classificando em produtos da indústria de transformação ${ }^{3}$ e produtos não classificados na indústria de transformação (NCIT), ${ }^{4}$ nota-se que os valores das exportações industriais são superiores às exportações NCIT. Entretanto, o ritmo de crescimento é diferente, sendo que, enquanto as exportações de produtos NCIT tiveram uma CAGR de 11,60\%, as exportações industriais apresentaram uma CAGR de 5,81\%.

Por outro lado, as importações apresentam uma dinâmica diferente, em que a Taxa de Crescimento Anual Composta das importações industriais é de 5,62\% e a CAGR das importações de NCIT é de 4,07\%. Para o período analisado, as importações industriais superam as importações de produtos NCIT, o que reafirma o argumento da desindustrialização, visto que no Brasil importam-se mais produtos com alto valor agregado.

Comparando-se, é possível perceber que as importações industriais crescem no mesmo ritmo das exportações industriais no período todo, com um agravamento negativo do saldo a partir de 2009. Assim, isso pode significar que exportações e importações evoluem, de certo modo, dentro do mesmo ritmo, variando de acordo com o ritmo de expansão da economia. Em outros termos, as importações se expandem num ritmo similar às exportações; portanto, podese inferir que não há redução da capacidade de oferta interna. Entretanto, esse cenário sofre alterações a partir de 2009.

\footnotetext{
${ }^{2}$ Compound Annual Growth Rate $(\mathrm{CAGR})=\left[(\text { valor final } / \text { valor inicial })^{1 / n}\right]-1 . \mathrm{n}=$ número de períodos.

${ }^{3}$ Indústria que transforma matéria-prima em utensílios, que podem ser bens de produção ou indústria de base e bens de consumo.

${ }^{4}$ Incluem-se os demais setores, inclusive commodities.
} 
Desagregando os dados das exportações e importações dos Setores Industriais por Intensidade Tecnológica (SIIT), buscamos avaliar o comportamento de acordo com a Intensidade Tecnológica (IT). Se a indústria como um todo perde importância relativa nas exportações, é importante investigar como se comporta cada SIIT em relação a essa perda.

O Gráfico 1 demonstra que a indústria brasileira é predominantemente exportadora de produtos de baixa, média-alta, média-baixa e alta intensidade tecnológica, por ordem de importância relativa. Seria de se esperar que a segunda maior exportadora fosse média-baixa IT. Nesse contexto, a indústria brasileira exporta mais baixa e média-alta IT, o que é uma indicação não desprezível do grau relativo de complexidade tecnológica dessa indústria, mesmo com predomínio da baixa intensidade tecnológica.

Dando sequência à análise, o Gráfico 2 corrobora a hipótese de que a estabilidade da participação das importações significa manutenção relativa das atividades industriais. Conforme demonstram os dados, a economia brasileira é primordialmente importadora de média-alta, alta, média-baixa e baixa intensidade tecnológica, respectivamente.

Gráfico 1 - Comparativo da evolução das participações das exportações de acordo com a IT 1997-2018 (Unidade de medida - Decimal $* 100=\%$ )

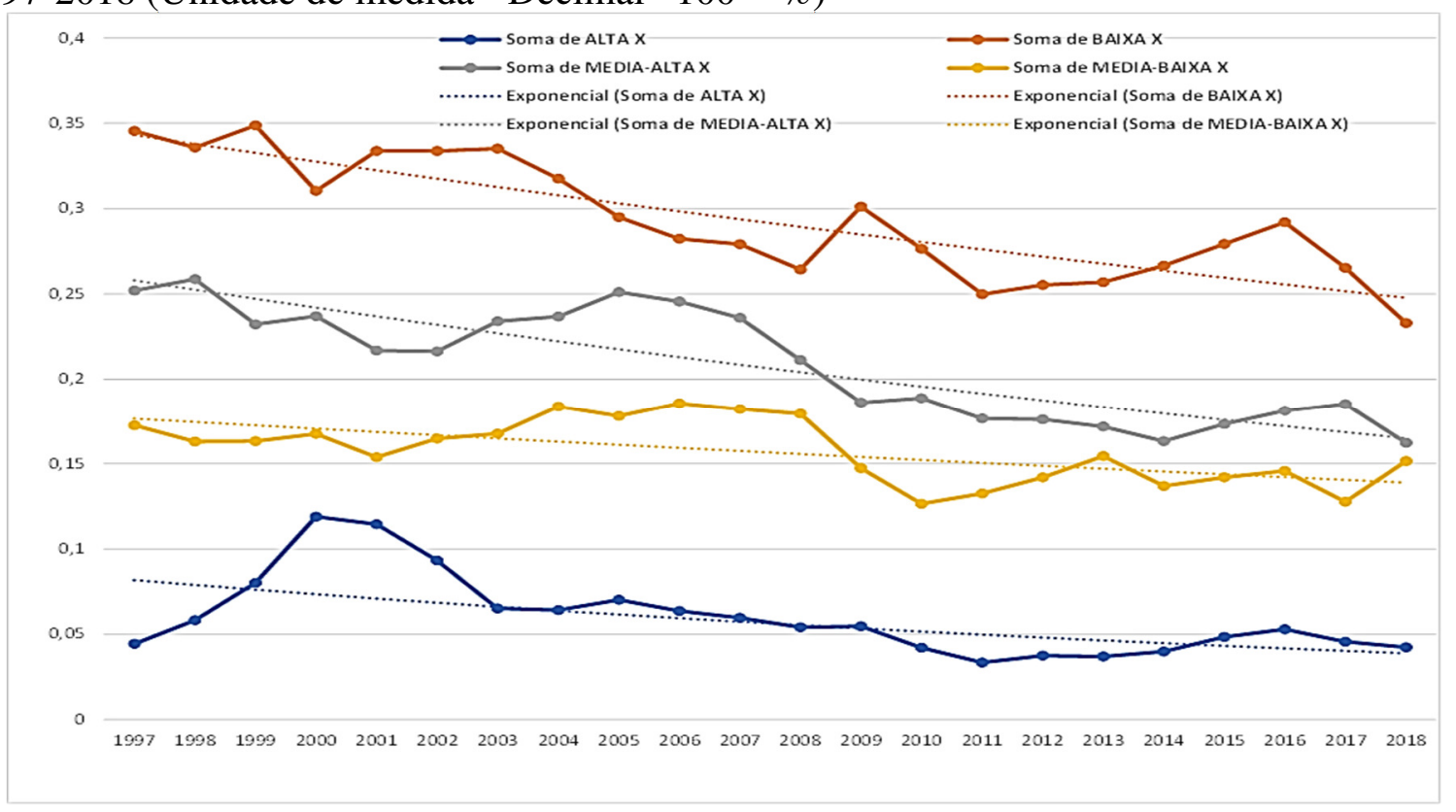

Fonte: Elaborado pelas autoras ${ }^{5}$ com base em dados da FIEP.

\footnotetext{
${ }^{5}$ Os dados explanados nos Gráficos 1 e 2 foram coletados em pesquisa de campo pela autora Pollyanna durante o estágio de pós-doutorado em Políticas Públicas na Universidade Federal do Paraná, em parceria com Walter Tadahiro Shima e Roberto Antônio Peredo Zurcher, com apoio financeiro da CAPES.
} 
Gráfico 2 - Comparativo da evolução das participações das importações de acordo com a IT $-1997-2018$ (Unidade de medida - Decimal $* 100=\%$ )

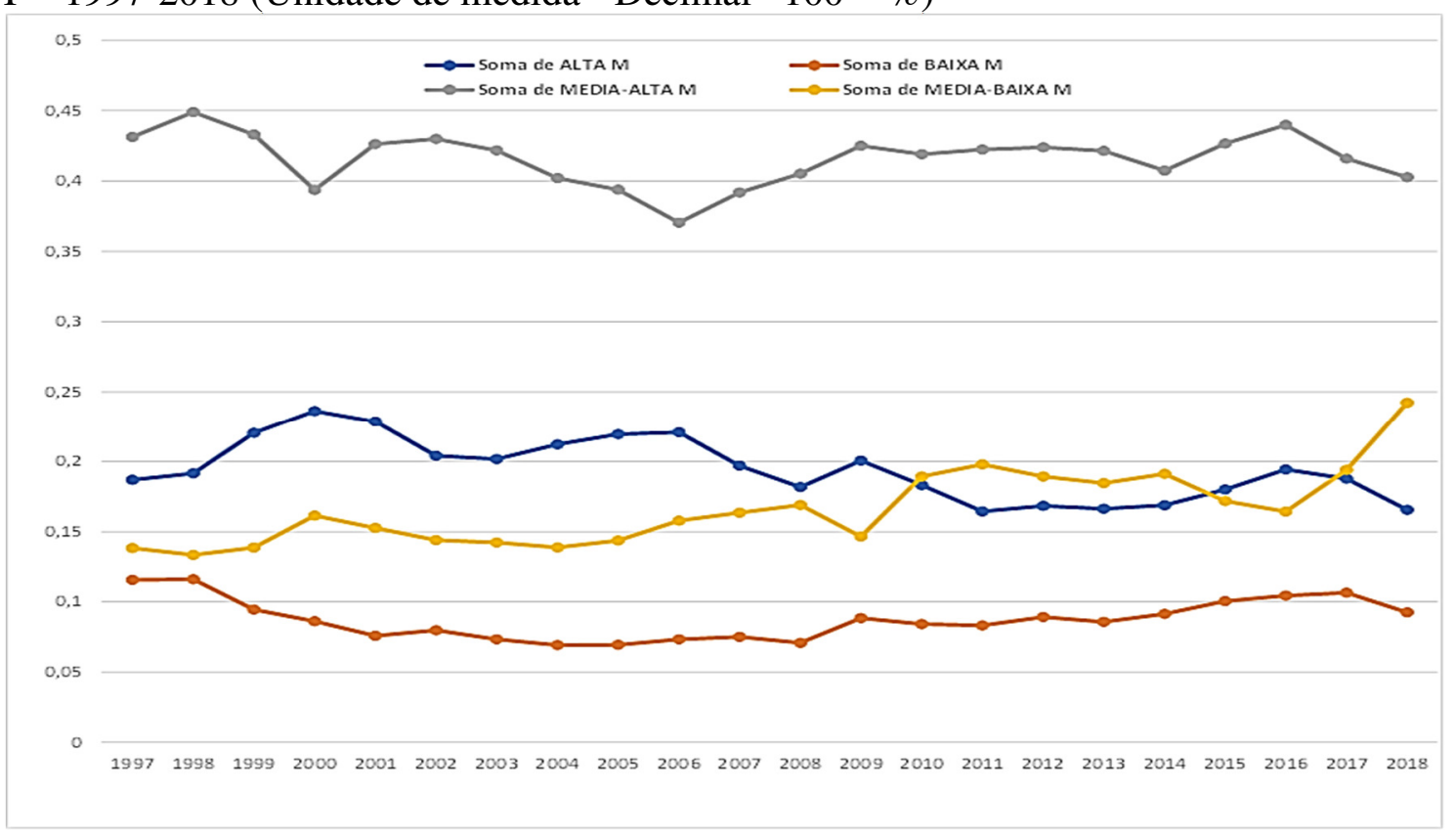

Fonte: Elaborado pelas autoras com base em dados da FIEP.

Em geral, observamos então uma relativa estabilidade entre importação e exportação no período em análise. Por outro lado, avaliando a desagregação dos dados, verificamos que as exportações de NCIT se expandem em um ritmo elevado, representando o dobro das exportações industriais. Vale enfatizar, também, que o crescimento das exportações de NCIT se deve fundamentalmente à participação de commodities. Corroborando os escritos furtadianos, o Brasil continua sendo considerado um país subdesenvolvido e a grande participação das commodities na pauta exportadora reforça que o crescimento da produtividade não é condição per se, para que se produza o verdadeiro desenvolvimento. Além disso, o peso das commodities nas exportações brasileiras, a importação de produtos de alta intensidade tecnológica, somados ao câmbio desvalorizado, reforça a tese de que o subdesenvolvimento não é uma etapa do desenvolvimento, mas sim uma condição estrutural do capitalismo.

Soma-se a essas informações, a análise do Investimento Direto Externo (IDE) e da Formação Bruta de Capital Fixo (FBCF). Nos três primeiros trimestres de 2019, o valor do IDE proveniente de Estados Unidos, China, Japão, Itália e França foi de US\$30,8 bilhões. Segundo o Ministério da Economia (2019), esse valor representou um aumento de aproximadamente 140\% no fluxo de IDE no Brasil. Esses dados podem ser visualizados no Gráfico 3. 
Gráfico 3 - Valor do acumulado anual de IDE confirmado, 2003 - 2019 - US\$ milhões

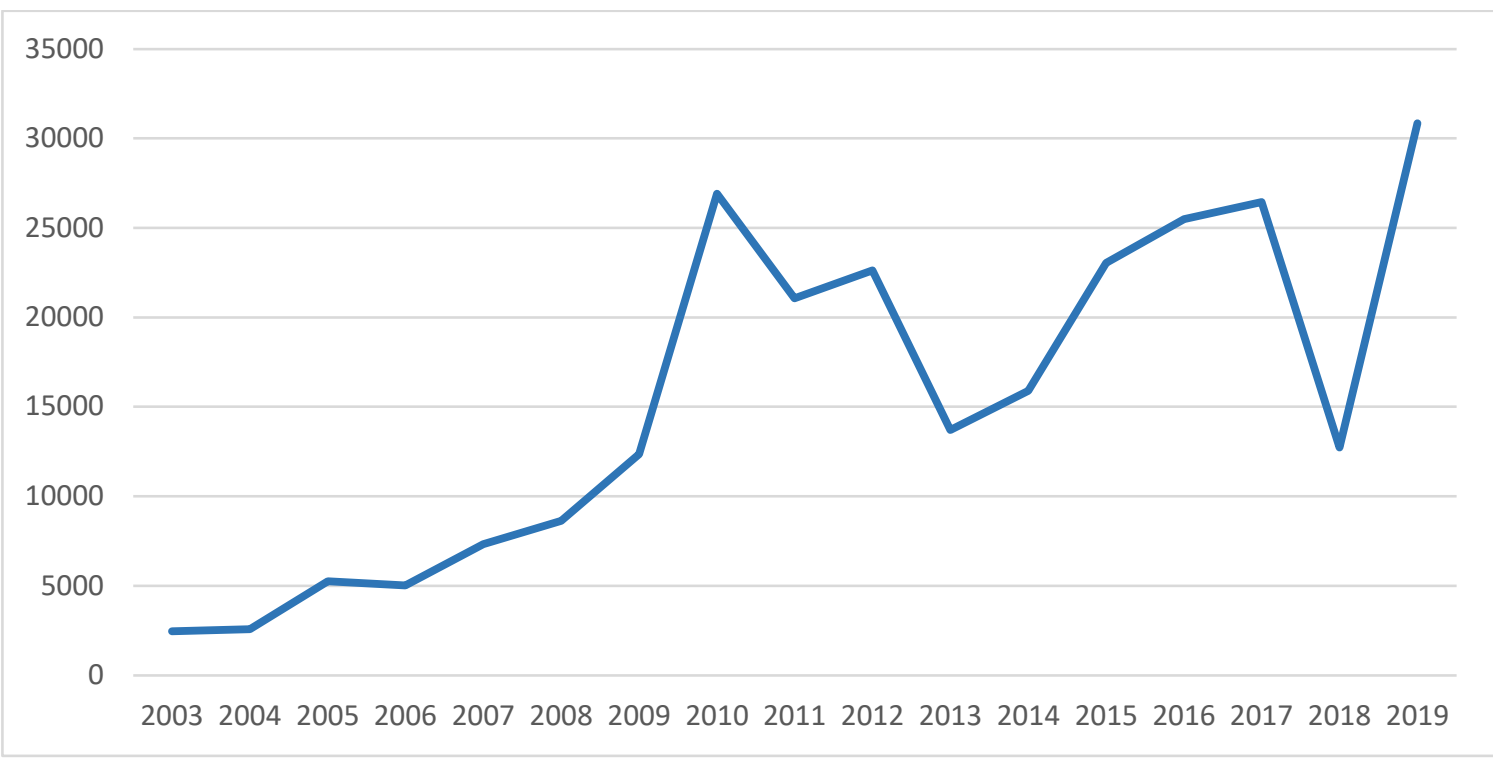

Fonte: Ministério da Economia/SE-CAMEX (2019).

A respeito do IDE de Estados Unidos, China, Japão, Itália e França, o relatório emitido pelo Ministério da Economia (2019, p. 7) afirma que:

De 2003 a 2019 (acumulado até o $3^{\circ}$ trimestre), os investimentos norte-americanos, em termos de valor, representaram $31,2 \%$ dos investimentos dos cinco países selecionados, e os chineses $30,9 \%$. Os investimentos franceses e japoneses, por sua vez, representaram 14,5\% e 14,2\% respectivamente. Os investimentos italianos representaram apenas $9,2 \%$ dos investimentos confirmados no Brasil nesse período, conforme mostrado pelos gráficos 8 e 9 . Considerando apenas o acumulado em 2019 , os investimentos italianos e franceses se destacam e representam, respectivamente, $43 \%$ e $32 \%$ do total. Os investimentos japoneses corresponderam a $16 \%$, os chineses a $6 \%$ e os norte-americanos apenas $2 \%$ do total investido pelos cinco países neste ano.

No que diz respeito à Formação Bruta de Capital Fixo (FBCF), a partir da Tabela 2, evidencia-se de 2013 e 2019 houve uma retração de seus componentes, como, por exemplo, máquinas e equipamentos, veículos, caminhões e ônibus e indústrias diversas.

Tabela 2 - Contribuição dos componentes selecionados da Formação Bruta de Capital do Brasil, 2013-2019 (Variação \%)

\begin{tabular}{l|c|c|c|c}
\hline & Peso & Contração & Expansão & Total \\
\cline { 2 - 5 } & & $\mathbf{2 0 1 3}$ a 2016 & $\mathbf{2 0 1 7}$ a 2019 & 2013 a 2019 \\
\hline Máquinas e equipamentos & 46,4 & $-19,3$ & 4,6 & $-16,6$ \\
\hline Veículos & 14,2 & $-5,3$ & $-2,3$ & $-6,7$ \\
\hline Caminhões e ônibus & 11,2 & $-12,5$ & 9,8 & $-6,9$ \\
\hline Indústrias diversas & 21,6 & $-6,0$ & 7,2 & $-1,9$ \\
\hline $\begin{array}{l}\text { Outros equipamentos de } \\
\text { transporte }\end{array}$ & 4,4 & 0,2 & 0,6 & 0,6 \\
\hline
\end{tabular}

Fonte: Banco Central do Brasil (2019). 
Os dados da Tabela 2 podem ser confirmados com a análise do Gráfico 4, em que há uma expansão significativa da FBCF no ano de 2009, decorrente, em grande medida, das iniciativas do governo brasileiro diante da crise imobiliária dos Estados Unidos. Entretanto, essa expansão não se mantém, sofrendo queda gradual nos anos subsequentes.

Gráfico 4 - PIB - Formação Bruta de Capital Fixo - variação de estoque - ,1995 - 2019, índice (base 2010=100)

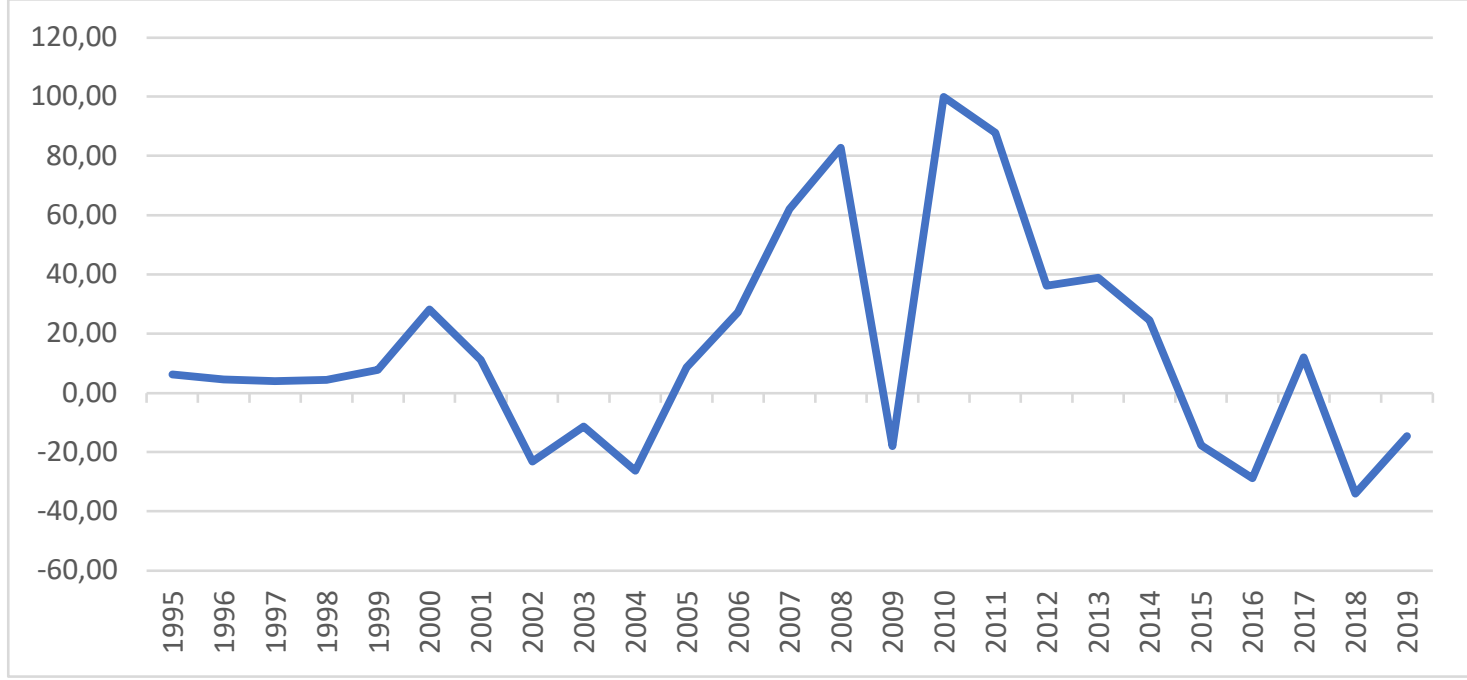

Fonte: IPEA Data (2010), elaborado pelas autoras.

Corroborando a análise de Sarti e Laplane (2002) para os anos 1990, a presente observação sobre o IDE e a FBCF demonstra que a contradição entre ambos permanece nos anos 2000. Nesse contexto, o aumento do IDE não se refletiu na ampliação da capacidade produtiva brasileira, visto que o país permaneceu em condição de dependência externa.

\section{Considerações finais}

O presente trabalho apresentou inicialmente a hipótese de que o subdesenvolvimento recente no Brasil está associado à intensificação do processo de desindustrialização precoce. À luz da interpretação de Furtado, sabemos que o subdesenvolvimento não é uma etapa do desenvolvimento, mas uma condição estrutural que requer rupturas.

Essas rupturas fazem-se necessárias em diversos âmbitos, a fim de que se alcance a homogeneização social é preciso superar a condição do subdesenvolvimento. Enquanto recorte metodológico, analisamos aqui, prioritariamente, a via do progresso técnico, visto que para Furtado a autonomia tecnológica é condição essencial para que se alcance essas rupturas, sobretudo de dependência com o comércio exterior. 
Em um cenário ideal, deveríamos penetrar nos mercados internacionais, ampliando a participação com tecnologias de vanguarda em detrimento dos produtos primários. Porém, os dados aqui ilustrados demonstram que o Brasil ainda está distante da autonomia tecnológica à qual Furtado (1992) fez referência. Infelizmente, ainda estamos mais voltados às políticas anticíclicas de recuperação de crises do que propriamente a um projeto amplo de desenvolvimento.

Apesar de a balança comercial brasileira apresentar, grosso modo, uma dada estabilidade, o saldo positivo não implica reconhecer que estamos em uma linha ascendente de industrialização, progresso técnico e desenvolvimento. Avaliando a desagregação dos dados, vimos que as exportações de NCIT (que incluem produtos primários) se expandem em um ritmo elevado, representando o dobro das exportações industriais. No âmbito da importação, a dependência externa se acentua, visto que ainda importamos prioritariamente produtos de média-alta e alta tecnologia.

Outra contradição que evidencia um cenário de dependência e desindustrialização é a relação entre o IDE e a FBCF. O IDE sugere a princípio a ampliação do grau de internacionalização; esse seria um cenário positivo se o investimento estrangeiro promovesse aumento na taxa de investimento interno da economia brasileira. Mas as evidências demonstram que isso não aconteceu, dada a contração nas taxas da FBCF, sobretudo no que se refere a máquinas e equipamentos.

Será que estamos sofrendo novamente uma internacionalização introvertida em meio a esse processo de desindustrialização precoce? Se há aumento do IDE sem contrapartida na FBCF, é provável que sim, até mesmo porque permanecemos na dependência externa de produtos com alto teor tecnológico. Embora o ritmo de IDE aponte para o aumento do nível de internacionalização da economia brasileira, esta não vem acompanhada pelo desenvolvimento do progresso técnico, o que reafirma a tese de que seguimos pela via da desindustrialização precoce e, consequentemente, do subdesenvolvimento.

Auferir a garantia do que é humanamente essencial a todos é um sonho que herdamos de Celso Furtado. Sendo o desenvolvimento do progresso técnico uma das vias para a superação do subdesenvolvimento, constatamos aqui que ainda há muito a ser percorrido rumo ao desenvolvimento e à homogeneidade social. 


\section{Referências}

\section{BANCO CENTRAL DO BRASIL. Evolução recente da Formação Bruta de Capital Fixo.} Estudo Especial $\mathrm{n}^{\circ}$ 63/2019. Obtido em: https://www.bcb.gov.br/conteudo/relatorioinflacao/EstudosEspeciais/EE063_Evolucao_recent e_da_formacao_bruta_de_capital_fixo.pdf Acesso em: 24 nov. 2020.

BRESSER-PEREIRA, L. C. The dutch disease and its eutralization: a ricardian approach, Revista de Economia Política, v. 28, nº 1, p. 47-71, 2008.

BRESSER-PEREIRA; L. C.; MARCONI, Nelson. Existe doença holandesa no Brasil? In: IV Fórum de Economia de São Paulo, 2008. Anais do IV Fórum de Economia de São Paulo: Fundação Getúlio Vargas, São Paulo, 2008.

CANO, W. A desindustrialização no Brasil. Economia e Sociedade, Campinas, v. 21, n. 4, p. 831-851, 2012. Disponível em: https://periodicos.sbu.unicamp.br/ojs/index.php/ecos/article/view/8642273. Acesso em: 22 nov. 2012.

CARDOSO DE MELLO, J. M. O capitalismo tardio. São Paulo: Editora Brasiliense, 1982. FUNDAÇÃO GETÚLIO VARGAS - FGV. A desindustrialização brasileira em debate. Carta do IBRE - Conjuntura Econômica, v. 64, n. 8, 2010. Obtido em: http://www.fgv.br/mailing/ibre/carta/agosto.2010/CIBRE_agosto_2010.pdf. Acesso em: 30 jan. 2018.

FURTADO, C. O subdesenvolvimento revisitado. Economia e Sociedade, v. 1, p. 5-19, ago. 1992.

LIMA, H. Manter e ajustar a política de conteúdo local - no Brasil, a desindustrialização precoce é um retrocesso. El País, 2017. Obtido em: http://www.jornalgrandebahia.com.br/wpcontent/uploads/2018/01/Manter-e-ajustar-a-pol\%C3\%ADtica-de-conte\%C3\%BAdolocal.pdf. Acesso em: 30 jan. 2018.

MARQUETTI, A. Progresso técnico, distribuição e crescimento na economia brasileira: 19551998. Estudos Econômicos, v. 32, n.1. p.103-124, 2002.

MINISTÉRIO DA ECONOMIA. Boletim de investimentos estrangeiros - Países selecionados, n. 3, jul. - set. 2019. Disponível em: https://www.gov.br/economia/pt-br/centraisde-conteudo/publicacoes/boletins/boletim-de-investimentos-estrangeiros/arquivos/boletim-deinvestimentos-estrangeiros-2013-paises-selecionados-3o-trimestre-de-2019. Acesso em: 23 nov. de 2020.

MORCEIRO, P. C. Desindustrialização na economia brasileira no período de 2000 a 2011: abordagens e indicadores. 2012. 219f. Dissertação (Mestrado em Economia) - Faculdade de Ciências e Letras, Universidade Estadual Paulista, Araraquara, 2012.

OREIRO, J. L; FEIJÓ, C. A. Desindustrialização: conceituação, causas, efeitos e o caso brasileiro. Revista de Economia Política, vol. 30, nº 2, p.292-232, 2010. Disponível em: 
http://www.scielo.br/scielo.php?script=sci_arttext\&pid=S0101-31572010000200003. Acesso em: 29 de jan. 2018.

SARTI, F.; LAPLANE, M. O investimento direto externo estrangeiro e a internacionalização da economia brasileira nos anos 90. Economia e Sociedade, v. 11, n. 1 (18), p. 63-94, jan./jun. 2002.

SILVA, A. L. G.; LAPLANE, M. F. Dinâmica recente da indústria brasileira e desenvolvimento competitivo. Economia e Sociedade, v. 3, n. 1, p. 81-97, 1994. Disponível em: https://periodicos.sbu.unicamp.br/ojs/index.php/ecos/article/view/8643219. Acesso em: 30 jan. 2018.

SILVA, J. A. A questão da desindustrialização no Brasil. Revista Economia e Tecnologia, v. 10, n. 1, p. 45-75, 2014. Disponível em: http://revistas.ufpr.br/ret/article/viewFile/32888/23265 Acesso em: 30 jan. 2018. 